04

\title{
Оптические и кинетические характеристики импульсного разряда в гелии с парами железа при атмосферном давлении
}

\author{
() В.С. Курбанисмаилов, ${ }^{1}$ С.А. Майоров, ${ }^{2,3,4}$ О.А. Омаров, ${ }^{1}$ Г.Б. Рагимханов ${ }^{1, \text { ॠ }}$ \\ ${ }^{1}$ Дагестанский государственный университет, \\ 367000 Махачкала, Россия \\ ${ }^{2}$ Институт общей фризики им. А.М. Прохорова РАН, \\ 119991 Москва, Россия \\ ${ }^{3}$ Объединенный институт высоких температур РАН, \\ 125412 Москва, Россия \\ ${ }^{4}$ Научно-исследовательский институт экспериментальной и теоретической фризики КазНУ им. аль-Фараби, \\ 050040 Алматы, Казахстан \\ ฯ e-mail: gb-r@mail.ru
}

(Поступило в Редакцию 26 июня 2018 г.)

При исследовании импульсного разряда в гелии атмосферного давления в спектре излучения прикатодной плазмы обнаружены линии паров материала электродов. Путем численного моделирования кинетики электронов методом Монте-Карло показано, что добавки атомов железа в гелий, начиная с долей процента, сильно влияют на ионизационно-дрейфовые характеристики электронов в газе.

DOI: 10.21883/JTF.2019.03.47173.251-18

Известно, что переходу от объемной формы горения к искровому каналу предшествует либо взрыв микроострий катодной поверхности, либо происходит инициирование эмиссионного центра при пробое диэлектрических включений [1]. Следовательно, в исходный газ может попадать некоторое количество атомов материала, из которого изготовлены электроды $[2,3]$. Хорошо известно $[4,5]$, что добавление в инертный газ с большим потенциалом ионизации даже небольшого количества легко ионизуемого газа (например, аргон в гелий [4] или криптон в гелий [6]) может радикально менять кинетические характеристики разряда. При этом решающую роль играют два фактора: 1 - легко ионизируемые добавки приводят к изменению зарядового состава; 2 - ионы примеси при движении в несобственном газе не испытывают столкновений с резонансной перезарядкой, поэтому их функция распределения радикально отличается от случая, когда ионы дрейфуют в родительском газе [7].

Поэтому экспериментальное исследование спектрального состава излучения приэлектродной плазмы в $\mathrm{He}$ атмосферного давления в режиме распыления материала катода представляет практический интерес. Изучению влияния малых концентраций паров материала электродов на кинетические характеристики разряда посвящена настоящая работа

Экспериментальная установка описана в работах $[8,9]$. Разряд создавался между электродами из нержавеющей стали (катод - сплошной, анод - сетчатый) диаметром $4 \mathrm{~cm}$, удаленными друг от друга на расстояние $d=1 \mathrm{~cm}$. Генератор импульсных напряжений (ГИН) давал импульсы напряжения с амплитудой до $30 \mathrm{kV}$ и фронтом нарастания $\sim 10 \mathrm{~ns}$. Источник УФ излучения вспомогательного разряда создавал в гелии начальную концентрацию электронов $n_{e} \approx 108 \mathrm{~cm}^{-3}$. Покадровая съемка разряда осуществлялась с помощью электроннооптического преобразователя (ФЭР-2) и позволяла проследить развития свечения, начиная с концентрации заряженных частиц $\sim 10-12 \mathrm{~cm}^{-3}$. Интегральные картины свечения промежутка снимались с помощью цифровой камеры с высоким пространственным разрешением. Для выявления наиболее ярких спектральных линий, возбуждаемых в разряде, регистрировался панорамный спектр с помощью монохроматора-спектрографа MS-3504i.

В настоящей работе исследовались закономерности формирования спектра оптического излучения объемного разряда в гелии при различных энерговкладах в разряд (в режиме однородного горения, разряд с катодными пятнами и привязанными к ним диффузными каналами, контрагированный разряд).

На рис. 1 приведен панорамный спектр разряда в области длин волн $300-800 \mathrm{~nm}$, полученный при напряжении $U_{0}=12 \mathrm{kV}$. Видно, что в спектре разряда наряду с линиями испускания гелия имеются интенсивные линии железа.

С увеличением энерговклада растет интенсивность спектральных линий, и появляются новые линии гелия и железа. Наблюдения показывают, что спектр линий железа появляется и при малых энерговкладах, когда разрядный промежуток представляет собой столб однородной плазмы. Это означает, что линии паров материала электродов появляются не только из-за взрывных процессов на катоде, но и из-за эрозии (распыления) катода за счет ионной бомбардировки. Следует отметить, что ранее в работе [10] исследован источник излучения на парах электродов из различных металлов, в том числе демонстрируется излучение линий железа в импульснопериодическом разряде. 

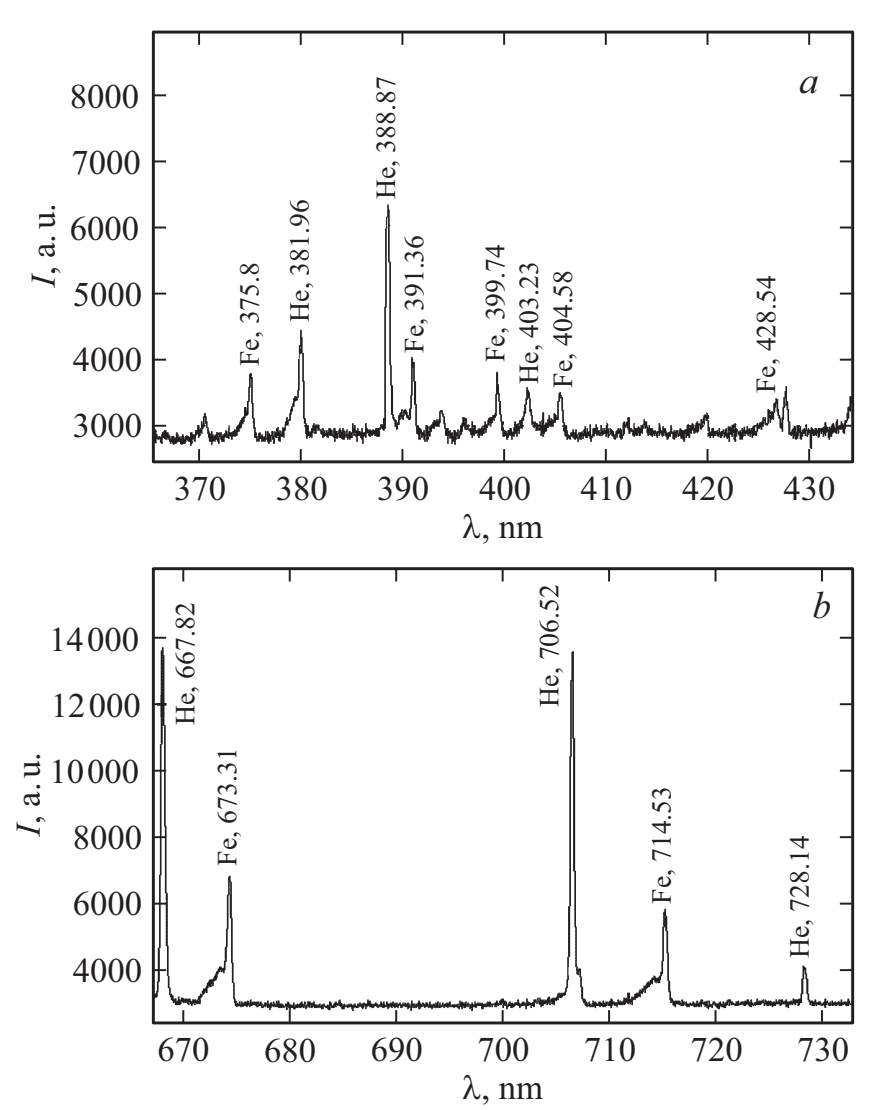

Рис. 1. Панорамный спектр разряда в гелии: $U_{0}=12 \mathrm{kV}$, $p=0.1 \mathrm{MPa}$.

Вычислительный эксперимент основан на рассмотрении ансамбля невзаимодействующих между собой электронов, движение которых определяется заданными полями и мгновенными столкновениями с атомами. Модель столкновений [7] использует процедуру генерации случайных чисел (метод Монте-Карло).

Розыгрыш электрон-атомных столкновений методом Монте-Карло позволяет учитывать энергобаланс электронов на основе элементарных актов, в том числе и неупругих. При розыгрыше столкновений учитывались известные зависимости сечений столкновений от энергии [11-13].

В настоящей работе рассчитывались значения скорости дрейфа, средней энергии электронов, характеристической энергии и ионизационного коэффициента Таунсенда с учетом примесей материала катода.

На рис. 2, а приведены зависимости скорости дрейфа электронов от приведенной напряженности электрического поля $E / N$ в чистом гелии и в чистом паре железа, а также дрейф в гелии с добавкой 1,10 и 50\% атомов железа (от общего количества атомов). Графики зависимостей скорости дрейфа показывают, что при добавлении в гелий паров железа вплоть до 10\% концентрации их атомов не приводит к заметному изменению скорости дрейфа, поскольку скорость дрейфа электронов при малых концентрациях железа определяется упругими столкновениями электронов с атомами гелия. В отличие от случая, когда в аргон добавляются пары ртути [14], добавление малых примесей железа в гелий не приводит к увеличению скорости дрейфа электронов, поскольку у гелия отсутствует эффект Рамзауэра.

На рис. 2, $b$ представлены зависимости приведенного ионизационного коэффициента Таунсенда $(\eta=\alpha / N$, который определяется как отношение числа пар, рожденных на $1 \mathrm{~cm}$, к числовой плотности атомов) от $E / N$. Результаты для ионизационного коэффициента Таунсенда рассчитаны в чистом гелии, в парах железа, а также с $0.1,1,2,5,10$ и 50\% содержанием атомов железа в гелии. Эти графики показывают, что даже $0.1 \%$ концентрации атомов железа при $4 \mathrm{Td}<E / N<60 \mathrm{Td}$ полностью меняет зарядовый состав и значительно понижает порог поля, при котором начинается значительная ионизация атомов газа.

В эксперименте обычно косвенным образом измеряется характеристическая энергия Таунсенда, которая определяется отношением коэффициента поперечной диффузии к подвижности $e D_{\perp} / \mu$ от $E / N$, которая равна температуре только в случае распределения Максвелла,
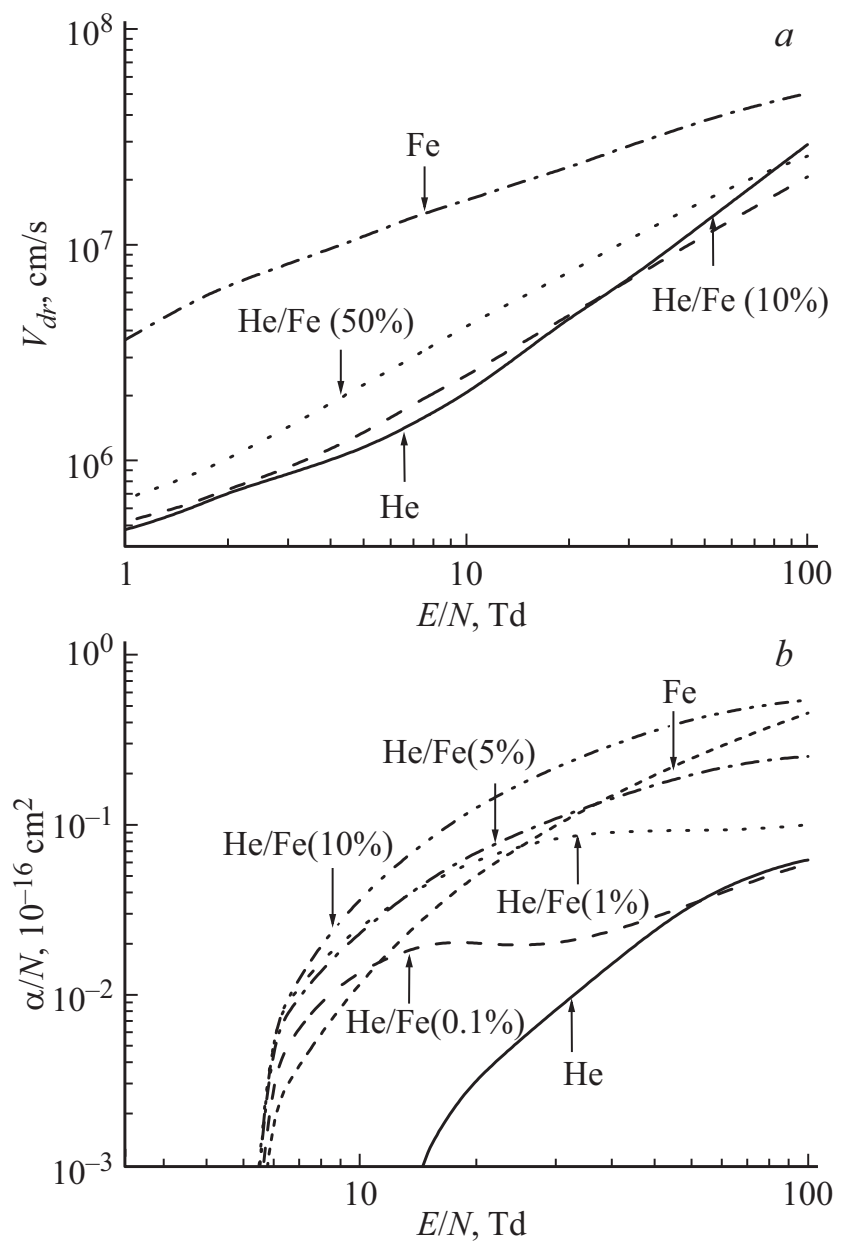

Рис. 2. Зависимости скорости дрейфа электронов $(a)$ и приведенного ионизационного коэффициента Таунсенда $\alpha / N(b)$ от $E / N$. 

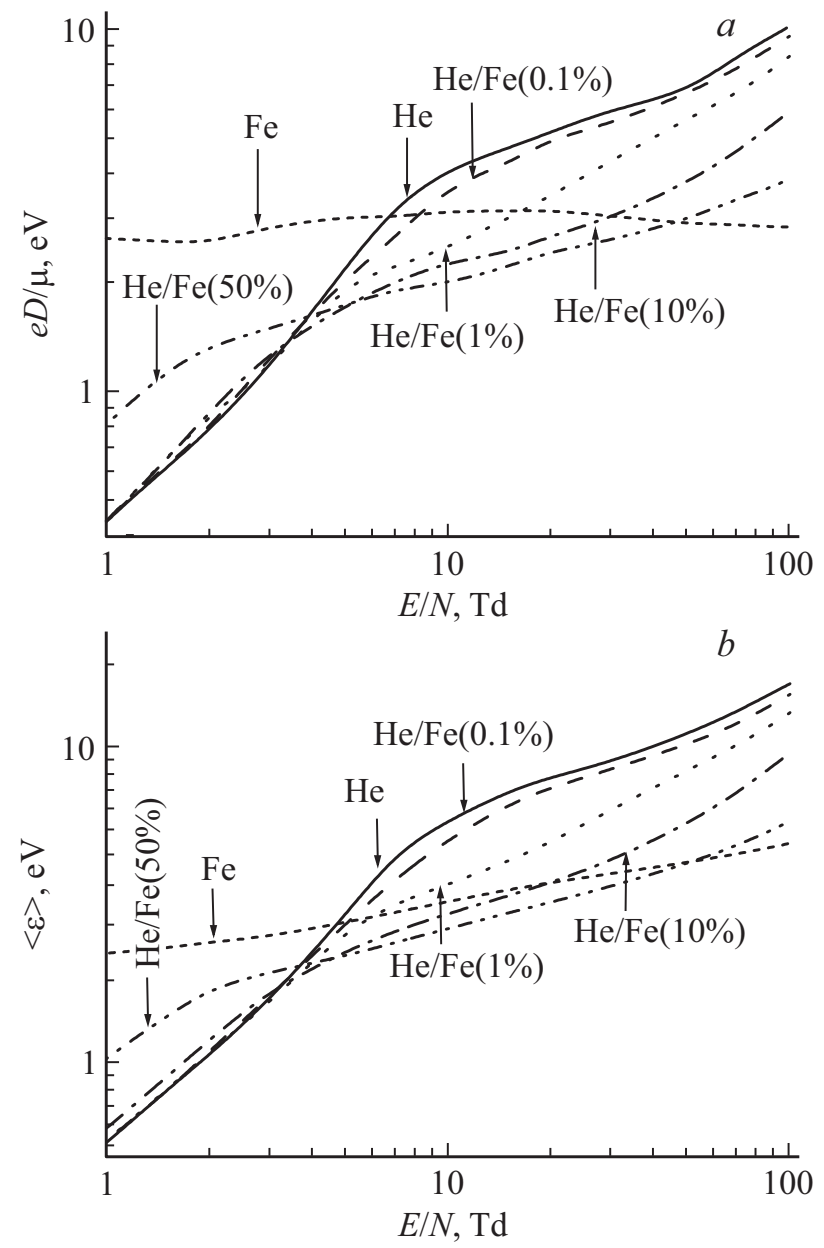

Рис. 3. Зависимости характеристической энергии Таунсенда $e D_{\perp} / \mu(a)$ и средней энергии $(b)$ электронов от $E / N$.

а в реальности характеристическая энергия Таунсенда может значительно отличаться от двух третей средней энергии электронов.

На рис. 3, $a$ приведены зависимости характеристической энергии Таунсенда, а на рис. $3, b$ зависимости средней энергии электронов от приведенной напряженности электрического поля $E / N$ в чистом гелии, в парах железа и с $0.1,1,2,5,10$ и 50\% содержанием атомов примесей железа в гелии. Здесь обозначения аналогичны предыдущему рисунку. Приведенные на рис. 3 графики позволяют оценить разницу между температурой и характеристической энергией Таунсенда, а их анализ сделать следующие выводы:

1) небольшие добавки паров железа в гелий оказывают сильное влияние не только на зарядовый состав плазмы, но и на функцию распределения электронов по энергии и ее средние характеристики;

2) имеется значительное отклонение от широко используемого соотношения Нернста-Таунсенда-Эйнштейна (часто называемого соотношением Эйнштейна) [15] между температурой и характеристической энергией Таунсенда $e D_{\perp} / \mu$, которая обычно и является определяемой в эксперименте величиной.

Результаты расчетов дают достаточно полную картину о механизме влияния малых добавок паров железа на характеристики газового разряда в гелии. Наиболее интересным и важным с практической точки зрения фактом является сильное увеличение частоты ионизации при незначительной (порядка долей процента) добавке паров железа. Кроме того, следует отметить, что в этом случае преимущественно будут ионизоваться атомы железа соответственно в разряде будут в основном представлены ионы железа.

Приведенные результаты расчетов позволяют проследить за влиянием процентного состава атомов железа в гелии на характеристики дрейфа электронов в постоянном и однородном электрическом поле с напряженностями в интервале от 1 до $100 \mathrm{Td}$. Следует отметить, что распыление катода имеет место практически при любых экспериментах с разрядами, и приведенные расчеты показывают, что изменение характеристик разряда при малых добавках легко ионизуемой примеси может быть использовано при поиске новых активных сред для различных плазменных технологий в микроэлектронике, обработке материалов, нанесении тонких пленок, создании источников света, плазменных панелях, медицине.

Таким образом, разряд в гелии с парами железа обладает особенностями, которые могут быть полезны при поиске новых и более эффективных источников излучения, а возможность значительно влиять на параметры разряда с помощью выбора состава смеси и ее процентного соотношения представляется чрезвычайно интересной.

Работа выполнена при частичной поддержке гранта РФФИ № 18-08-00075a.

\section{Список литературы}

[1] Королев Ю.Д., Месяи Г.А. // Физика импульсного пробоя газов. М.: Наука, 1991. 224 с.

[2] Курбанисмаилов В.С., Омаров О.А., Рагимханов Г.Б., Арсланбеков М.А., Абакарова Х.М., Али Р. А.А. // Успехи прикладной физики. 2014. Т. 2. № 3. С. 234-242.

[3] Ломаев М.И., Белоплотов Д.В., Сорокин Д.А., Тарасенко В.Ф. // ОПт. и спектр. 2016. Т. 120. № 2. С. 179-183.

[4] Maiorov S.A., Ramazanov T.S., Dzhumagulova K.N., Jumabekov A.N., Dosbolaev A.N. // Phys. Plasmas. 2008. Vol. 15. P. 093701.

[5] Бохан П.А., Закревский Д.Э. // ЖТФ. 1997. Т. 67. Вып. 4. C. 25-31.

[6] Antipov S.N., Vasil'ev M.M., Maiorov S.A., Petrov O.F., Fortov V.E. // J. Experiment. Theor. Phys. 2011. Vol. 112. N 3. P. 482-493.

[7] Майоров С.А. // Физика плазмы. 2009. Т. 35. № 9. С. 869 880.

[8] Курбанисмаилов В.С., Омаров О.А., Рагимханов Г.Б., Абакарова Х.М., Али Р.А.А. // Физика плазмы. 2016. T. 42. № 7. C. 680-692. 
[9] Курбанисмаилов В.С., Омаров О.А., Рагимханов Г.Б., Терешонок Д.В. // Письма в ЖТФ. 2017. Т. 43. Вып. 18. C. $73-81$.

[10] Бакшт Е.Х., Тарасенко В.Ф., Шутько Ю.В., Ерофеев М.В. // Квантовая электроника. 2001. Т. 42. № 2. С. 153 156.

[11] Мак-Даниэль И. Процессы столкновений в ионизованных газах. М.: Мир, 1967.

[12] Смирнов Ю.М. // Квантовая электроника. 2000. Т. 30. № 11. C. 1019-1024.

[13] Bartlett P.L., Stelbovics A.T. // Phys. Rev. A. 2002. Vol. 66. P. 012707.

[14] Golyatina R.I., Maiorov S.A. // Plasma Phys. Reports. 2018. N 4. P. 5-10.

[15] Хаксли Л., Кромптон Р. Диффузия и дрейф электронов в газах. М.: Мир, 1977. 